\title{
A cooperação Sul-Sul brasileira em HIV/AIDS: a doação de antirretrovirais como soft power do Brasil no cenário internacional
}

\author{
Brazilian South-South cooperation on HIV/AIDS: \\ the donation of anti-retrovirals as soft power of \\ Brazil in the international scenario
}

DOI: $10.21530 /$ ci.v13n3.2018.795

Fabiola Faro Eloy Dunda ${ }^{1}$

\section{Resumo}

A cooperação Sul-Sul brasileira em saúde pode ser visualizada em vários campos da área, tais como no contexto dos bancos de leite humano, na doação de medicamentos antirretrovirais, nos projetos de combate à epidemia de HIV/AIDS em parceria com vários países e na participação com outros países no desenvolvimento de vacinas e medicamentos. No presente artigo, será analisada a cooperação Sul-Sul brasileira para o combate ao HIV/AIDS como soft power do país, por meio da doação de medicamentos antirretrovirais para países das Américas, África e Ásia entre os anos 2003 e 2016. Fontes de soft powertais como valores políticos, a personalidade de um líder, as instituições e a política externa do país - foram utilizadas para verificar como o Brasil exerceu poder de atração para outros países no sistema internacional, facilitando, nesse sentido, a demanda dos mesmos por cooperação na área. Conclui-se, ao final, que as fontes de soft power destacadas estiveram presentes na referida cooperação.

Palavras-chave: Cooperação Sul-Sul; AIDS; antirretrovirais; soft power; política externa brasileira.

\footnotetext{
Abstract

Brazilian South-South cooperation in health can be seen in various fields of the area, such as in the context of human milk banks, in the donation of antiretroviral drugs, in projects to fight the HIV/AIDS epidemic in partnership with several countries, as well as in the

1 Médica formada pela Universidade Federal da Paraíba (UFPB); Mestre em Relações Internacionais pela Universidade Estadual da Paraíba (UEPB); Doutora em Ciência Política pela Universidade Federal de Pernambuco (UFPE). Artigo submetido em 03/05/2018 e aprovado em 02/10/2018.
} 
participation with other countries in the development of vaccines and medicines. This article will analyze the Brazilian South-South cooperation to fight HIV/AIDS as the country's Soft power through the donation of antiretroviral drugs to countries in the Americas, Africa and Asia between the years 2003 and 2016. Sources of Soft power, such as political values, the personality of a leader, institutions, and the foreign policy of the country were used to verify how Brazil exerted power of attraction to other countries in the International System, thus facilitating the demand of them for cooperation in the area. It is concluded, in the end, that the highlighted sources of Soft power were present in this cooperation.

Keywords: South-South Cooperation; AIDS; antiretrovirals; Soft power; Brazilian foreign policy

\section{Introdução}

O conceito de cooperação Sul-Sul não encontra consenso entre aqueles que o estudam, mas observa-se que existe aquiescência no que se refere aos princípios que o regem. Para autores como Leite, Suyama e Waisbich (2013, p.1) a cooperação Sul-Sul entre países em desenvolvimento é definida como

ação que é regida pelos princípios de diplomacia solidária; é orientada pela lógica da demanda de países em desenvolvimento; reconhece a experiência local como parte importante para a execução de projetos, não exige condicionalidades, não vincula interesses comerciais ou fins lucrativos à execução dos projetos, e evita ingerência em assuntos internos dos países parceiros.

No âmbito brasileiro, o discurso oficial sobre a cooperação ressalta o não interesse econômico-comercial e a solidariedade entre os países em desenvolvimento como algumas das principais razões para se estabelecer ações no modelo Sul-Sul (ABC, 2018). Autores como Corrêa (2010) destacam que a cooperação Sul-Sul entre países em desenvolvimento preza pelo respeito à soberania; prima pela não ingerência nos assuntos internos dos países parceiros e apresenta vantagens comparativas frente à cooperação Norte-Sul, tais como custos operacionais menores, disponibilização de tecnologias e experiência e boas práticas desenvolvidas entre países em desenvolvimento.

Puente (2010) ressalta que as motivações de um país ou dos atores envolvidos na cooperação podem ser de cunho moral, humanitário e altruístico, e essa vertente estaria baseada em elementos filosóficos e religiosos, os quais fazem pressupor que países mais ricos e economicamente desenvolvidos teriam o dever moral de ajudar aqueles países em condições econômicas e sociais desfavoráveis. 
O autor destaca ainda como motivações para a cooperação, a ética, interesses econômico-comerciais, laços históricas e/ou culturais. Refletindo-se a partir dessas considerações, a cooperação Sul-Sul brasileira pode ser motivada não apenas pela solidariedade, como destacado no discurso oficial citado anteriormente, podendo haver também interesses políticos e econômicos nas ações estabelecidas com outros países.

O Brasil desenvolve cooperação em vários setores da área de saúde, tais como o combate à epidemia de HIV/AIDS e os bancos de leite humano (ABC, 2018). Destaca-se neste artigo a cooperação Sul-Sul para o combate ao HIV/AIDS, que tem na doação de medicamentos antirretrovirais para países da América do Sul, América Central, África e Ásia a sua vertente humanitária. No contexto desse modelo, ressalta-se a solidariedade como uma das molas propulsoras para a cooperação. O relatório da UNAIDS do ano de 2017 informou que existem, aproximadamente, trinta e seis milhões de pessoas contaminadas pelo vírus HIV no mundo e, dessas, apenas dezenove milhões estavam recebendo tratamento com antirretrovirais (UNAIDS DATA, 2017).

Nye (2004) refere que “poder” pode significar influência de um agente (Estado, instituições, organizações, indivíduo etc.) no sistema internacional e, nesse contexto, a influência funciona como poder de atração e aquiescência, e pode ser considerada como um instrumento de poder brando, ou soft power. Analisando-se a cooperação Sul-Sul brasileira no combate à epidemia de HIV/AIDS, a mesma não utiliza força ou coerção para estabelecer ações na área, podendo, nesse sentido, ser enquadrada no conceito de soft power, em que ideias como poder de atração, influência e persuasão são destacadas.

O tema abordado no presente artigo se justifica, inicialmente, por ser a saúde um assunto relevante nas relações internacionais e ainda com poucos estudos na área. A epidemia de HIV/AIDS continua afetando vários países, principalmente aqueles mais pobres economicamente, como os situados no continente africano. A cooperação na área é uma forma de tentar diminuir os impactos da doença nas sociedades atingidas, além de contribuir para que mais pessoas tenham acesso ao tratamento de uma doença ainda sem cura nos dias atuais.

No campo político, a cooperação na área de saúde é uma forma de atuação dos países no sistema internacional, destacando-se aqueles que têm mais expertise e a utilizam como meio de alcançar seus interesses. Nesse contexto, o Brasil, atuando por meio dessa cooperação específica, procura aumentar seu poder de influência utilizando instrumentos de soft power. 
O presente artigo analisa a vertente humanitária da cooperação Sul-Sul brasileira de combate ao HIV/AIDS por meio da doação de medicação antirretrovirais, entre os anos de 2003 e 2016. A metodologia utilizada foi o estudo de caso, com análise qualitativa e quantitativa, por meio de análise de conteúdo e estatística descritiva, respectivamente. Os dados referentes à doação de antirretrovirais foram solicitados ao Ministério das Relações Exteriores e ao Ministério da Saúde através do sistema eletrônico do serviço de informação ao cidadão (e-sic). O referencial teórico se baseia na teoria do soft power, cujo principal expoente é Joseph Nye, interconectando o que o autor considera como fontes de soft power e os dados referentes à doação de antirretrovirais pelo Brasil.

O artigo está divido em uma seção inicial que especifica de forma não aprofundada os princípios da cooperação Sul-Sul, o discurso brasileiro sobre o tema, as motivações da pesquisa, bem como o marco teórico sobre o qual o artigo se assenta e a metodologia utilizada. A seção um interconecta os conceitos de poder, saúde, política externa e soft power, abordando a relação e a influência entre saúde e política externa.

Na seção dois, são apresentados os dados referentes à doação de medicamentos antirretrovirais entre 2003 e 2016, que desagregados demonstram os gastos, os países, a área geográfica a que pertencem e a quantidade de medicamentos doados ao longo dos anos e dos governos dos presidentes Luiz Inácio Lula da Silva e Dilma Rousseff. A seção três aprofunda a temática analisando os dados, fazendo a correlação dos mesmos com as fontes de soft power. O artigo é concluído com algumas considerações finais.

\section{Poder, saúde, política externa e soft power: onde os conceitos se encontram?}

Poder é um conceito contestado, e que encontra entendimentos diferentes quanto ao seu significado. Poder pode estar relacionado ao binômio causa-efeito, ou seja, um agente que possua maior "poder" pode afetar o comportamento, as ações, as crenças de outro agente (BALDWIN, 1993). Waltz (1979) vai rejeitar o entendimento causal, e vai expressar a ideia de que o agente mais poderoso é aquele que tem a capacidade de afetar outros agentes muito mais do que ser afetado por eles (WALTZ apud BALDWIN, 1993). 
Poder pode ser entendido também como “capacidades”, e nesse sentido seria uma das formas de analisar a extensão da força de um agente, no caso, um Estado, no sistema internacional. As capacidades de um Estado poderiam se expressar através de componentes materiais e/ou imateriais de que o país dispõe, tais como a força militar, a economia, a cultura, a política doméstica/externa etc. Nesse sentido, medir-se-ia o poder de um ou mais Estado(s) sobre outro(s) no sistema internacional (BALDWIN, 1993).

Poder também se relaciona com a ideia de soma zero, ou seja, quando dois ou mais Estados entram em alguma disputa em determinada área de interesse no sistema internacional, se um deles obtiver mais vantagem e ganhos que o outro, esse será um jogo onde aquele que ganha implica necessariamente que o outro perde tudo (BALDWIN, 1993).

Bobbio (2017), sobre a ideia de poder, discorre sobre três teorias fundamentais concernentes ao assunto: a substancialista, a subjetivista e a relacional. Na primeira, poder é entendido como "uma coisa que se possui e se usa como outro bem qualquer "(BOBBIO,2017, p. 100); na segunda, o autor faz referência à interpretação subjetivista do poder² onde "poder seria não a coisa que serve para alcançar o objetivo, mas a capacidade de o sujeito alcançar certos efeitos”(BOBBIO, 2017, p. 101); e a terceira entende poder como "uma relação entre dois sujeitos, dos quais o primeiro obtém do segundo um comportamento, que, em caso contrário, não ocorreria ” (BOBBIO, 2017, p. 101)

Poder pode ser definido também como a habilidade de influenciar o comportamento dos outros para conseguir o(s) resultado(s) desejado(s), atuando por meio da coerção, da indução ou da atração. Quando um Estado tem capacidade de atrair outros Estados por meio de estratégias que geram atração, esse poder é entendido como soft power (NYE, 2004). Em sua essência, o soft power ${ }^{3}$ de um Estado seria a habilidade que o mesmo tem em moldar as preferências de outros Estados para a consecução de seus interesses e, de forma geral, “a habilidade

2 Ao se referir à teoria subjetivista, Bobbio (2017) reflete no texto à interpretação de poder dada por Locke (1694, II, XXI) quando este último faz a consideração de que “o fogo tem o poder de fundir os metais” do mesmo modo que o soberano tem o poder de fazer as leis e, fazendo as leis, de influir sobre a conduta de seus súditos.

3 Soft Power é um conceito desenvolvido por Joseph Nye Jr inicialmente em seu livro Bound to Lead, publicado em 1990, e inserido no contexto de discussão daquele período, de que a América estava em declínio. O próprio autor faz referência no prefácio de seu livro Soft Power. The means to success in world politics (2004) sobre esse fato e de como, a partir da criação desse conceito, o mesmo passou a ser utilizado em discursos públicos de líderes políticos, bem como no meio acadêmico. O autor retornou a discorrer sobre o tema de forma mais aprofundada em dois outros livros: The Paradox of American Power, publicado em 2001 e no referido anteriormente, publicado em 2004. 
de estabelecer preferência tende a ser associada a bens intangíveis tais como a personalidade, a cultura, os valores políticos e as instituições, e políticas que são vistas como legítimas ou tendo autoridade moral"4 (NYE, 2004, p.6).

As políticas empreendidas pelo país podem ser vistas como legítimas, ou tendo autoridade moral para serem implementadas, e, nesse sentido, soft power não seria simplesmente influenciar o sistema, mas também o quanto e como um Estado conseguiria exercer seu poder de atração no intuito de alcançar o interesse desejado (NYE, 2004, p. 6). Acrescenta-se que soft power é a "habilidade de atrair, e a atração frequentemente leva à aquiescência " 5 , e as fontes desse tipo de poder é que produzem essa atração, podendo ser encontradas primariamente na sua cultura, nos seus valores políticos e na sua política externa (NYE, 2004). A cultura como fonte de soft power tem um espectro abrangente, podendo ser considerada desde áreas que podem promover o conhecimento e/ou o entretenimento, tais como arte, literatura, educação, música etc., como também valores universais e políticas adotadas por determinada sociedade, e que despertam o interesse de outras sociedades para o compartilhamento daquelas ideias (NYE, 2004).

Soft power é um conceito que também encontra críticas dentre aqueles que o estudam. Fergunson (2009), discorrendo sobre fontes de poder, considera que fontes materiais de poder, tais como a militar, econômica e financeira, por exemplo, podem determinar, mas não necessariamente, que uma nação seja vista como grande potência no sistema internacional. Para o autor, no mundo globalizado, o poder militar depende também de crescimento econômico e instituições políticas. Destacando o papel do soft power, Ferguson (2009) considera que o não uso da força em domínios menos conflituosos, como a cultura e o comércio, não necessariamente levará a maior atração e influência de um país mais forte sobre outro menos forte em termos de poder, fazendo uma crítica direta ao conceito e ideia desenvolvidos por Joseph Nye nos anos de 1990.

Outro autor que tem um entendimento diferente de Joseph Nye sobre soft power é Matsuda (2007), que considera que o poder brando seria uma "via de mão dupla”, ou seja, na relação entre dois países haveria ao mesmo tempo influência e resistência nessa interação (MATSUDA apud DUTTA, 2018). Gray (2011) propõe também um olhar crítico sobre a análise do soft power no que tange ao conceito,

4 No original: "The ability to establish preferences tends to be associated with intangible assets such as an attractive personality, culture, political values and institutions, and polices that are seen as legitimate or having moral authority"

5 No original: "It is also the ability to attract, and attraction often leads to acquiescence" 
de onde ele vem e quem o controla, e qual é a qualidade e quantidade dessa potencial influência (GRAY, 2011). Para o autor, "cooptar” um país por influência não significa, necessariamente, que estaria havendo soft power e que os efeitos dessa ação seriam automaticamente positivos. Gray (2011) ressalta que, em algumas situações, a influência de um país sobre outro sem o uso da força e/ ou coerção pode ser negativa, gerando ressentimento, hostilidade e/ou outros sentimentos e/ou ações negativos não previstos na relação inicial. O autor defende que, em algumas ocasiões, a atração de países considerados menos potentes no sistema internacional, quando se refere aos Estados Unidos, pode ser resultado não necessariamente do poder brando exercido pelo mesmo, mas possivelmente pela ideia de que os Estados Unidos é visto e considerado como um país guardião no/do sistema internacional e que pode exercer (e exerce em algumas ocasiões) o papel de líder na formação de coalizões entre os Estados (GRAY, 2011).

Aprofundando um pouco mais o espectro de análise sobre soft power, particularmente no que concerne a uma de suas principais críticas - como se mede esse tipo de poder de um país no sistema internacional? -, McClory (2018) introduz instrumentos que possibilitam identificar e medir o soft power de forma mais concreta e menos subjetiva por meio de índices apresentados e expostos no relatório "Soft Power 30 index" (MCCLORY, 2018). O autor combina dados objetivos e subjetivos para medir o soft power de um país, colocando-os em ranking internacional. Os dados objetivos são distribuídos em seis categorias divididas em subíndices que pontuam individualmente. Os índices são governo, cultura, empresas, comprometimento global, digital e educação ${ }^{6}$. Os dados subjetivos são obtidos por meio de pesquisa/enquete internacional, realizadas atualmente em vinte e cinco países, e que incluem questões curtas que pontuam de 0-10, e se baseiam na percepção da população estudada sobre questões relativas à interação com outros países. O autor refere que existem limitações na metodologia aplicada, principalmente por serem os dados subjetivos difíceis de medir, quando se considera a complexidade dos mesmos, bem como a complexidade das inter-relações entre os Estados-nações (MCCLORY, 2018)

Saúde também é um conceito que tem ampla interpretação, podendo o termo ser entendido como a ausência de doença, como bem-estar ou ainda como valor social. Hodiernamente o conceito de saúde também está ligado aos determinantes

6 Os dados objetivos são pesquisados em várias fontes, estando as mesmas relacionadas diretamente ao tema pesquisado. Os dados medidos em cada índice referido no texto podem ser encontrados no apêndice do relatório “The Soft Power 30. A Global Ranking os Soft Power 2018”, disponibilizado nas referências. 
e condicionantes do complexo saúde-doença (BATISTELLA, 2007). Atualmente, defende-se que um conceito amplo de saúde deve considerar não apenas a ausência de doenças, mas a ausência ou a diminuição de condições socioambientais que possam causar as mesmas (BATISTELLA, 2007).

Saúde entendida como bem-estar é um conceito que está inserido no contexto da cooperação internacional, e previsto no documento constitutivo da Organização Mundial da Saúde de 1948. No referido documento, saúde passa a ser entendida como "um completo estado de bem-estar físico, mental e social, e não apenas a ausência de doença ou enfermidade” (BATISTELLA, 2007, p. 57). No contexto da cooperação internacional, a saúde é uma temática que se inter-relaciona com a política externa e, dessa estreita relação, a saúde pode ser negligenciada pela política externa, ou pode servir aos objetivos da mesma. Nesse segundo cenário, a saúde se transforma em um instrumento de política externa ou parte integral da mesma (KICHBUSCH, 2013).

No cenário em que a saúde é negligenciada pela política externa, pode-se usar como exemplo as sanções econômicas ou acordos de comércio e propriedade intelectual quando esses provocam efeitos deletérios na área de saúde pública. Exemplo dessa negligência foi o processo de negociação, em 2010, do acordo de livre-comércio entre a Índia e a União Europeia que, em uma de suas cláusulas, previa a exclusividade de dados, a extensão do tempo de patentes farmacêuticas para mais de vinte anos e medidas de fronteiras que podem afetar diretamente a questão da produção de medicamentos genéricos pela Índia, o que levaria ao prejuízo nacional e mundial de fornecimento de medicamentos, tais como o utilizado para o tratamento do HIV/AIDS (IDEC, 2018).

No outro extremo da relação, a política externa estaria servindo aos objetivos da saúde. Nesse contexto, a temática da saúde é discutida em fóruns internacionais e regionais, tais como a OMC, ONU, BRICS, IBAS, o G-20, Mercosul e outros, trazendo à tona questões de importância tanto para o sistema internacional, quanto para o âmbito regional e nacional (KICHBUSCH, 2013). Quando a saúde se torna instrumento e/ou parte integral da política externa, a temática serve aos interesses nacionais, aumentando a relação entre os países, tais como acordos, planos de assistência financeira ou humanitária e cooperação em diversas áreas. No momento em que eclodem problemas globais, tais como a epidemia de HIV/ AIDS, de H1N1 ou a recente epidemia de ebola na África Ocidental, por exemplo, a saúde é parte integral da política externa dos países, pois a solução de problemas globais envolve o esforço cooperativo e a participação de Estados que estão envolvidos direta ou indiretamente no problema em questão (KICHBUSCH, 2013). 
O início da institucionalização entre saúde e política externa remonta ao século XIX, no contexto da primeira Conferência Sanitária Internacional, em 1851, para discutir questões relacionadas ao comércio e navegação. Quase duzentos anos depois, políticas e acordos para problemas de saúde global, incluindo aqueles que transcendem as fronteiras nacionais, são discutidos principalmente na Organização Mundial da Saúde, uma das instituições criadas no pós II Guerra Mundial (KICHBUSCH, 2013). No contexto da relação saúde e política externa, autores que discutem a saúde global introduzem o conceito de diplomacia da saúde, entendido como "um método de alcançar compromisso e consenso em assuntos relativos ao tema, particularmente no caso de outros interesses relacionados à política internacional, interesses econômicos e valores éticos "7 (KICHBUSCH, 2013, p.11).

A política externa como fonte de soft power também pode funcionar como um instrumento que afeta a preferência de outros Estados (NYE, 2004). Nesse contexto, Nye (2004) ressalta que governos podem atrair ou repelir outros países pela influência de seu exemplo. Considerando a cooperação brasileira em saúde como parte integrante da política externa brasileira, particularmente a que se estabelece na área de combate ao HIV/AIDS, as ações desenvolvidas na área podem influenciar a relação do país com outros Estados como, por exemplo, através da doação de medicamentos antirretrovirais. No Brasil, o acesso universal ao tratamento pode ser identificado como uma das razões da manutenção da baixa prevalência da doença entre a população entre 15 e 45 anos, atualmente estimada em 0,6\% (BANCO MUNDIAL, 2018). A cooperação brasileira na área de combate ao HIV/AIDS permite que mais pessoas em outros países tenham mais acesso ao tratamento com os antirretrovirais, e naqueles países em que a prevalência da doença encontra-se ainda elevada, maior acesso ao tratamento pode levar também à diminuição do número de mortos e pessoas contaminadas, a exemplo do que ocorre na realidade brasileira.

As boas práticas do combate à epidemia no Brasil, com políticas públicas específicas orientadas para essa realidade e com resultados positivos quando se considera o tamanho da população do país e o número de pessoas contaminadas, refletidos na baixa prevalência da doença, podem ser fontes de atração de outros países para estabelecer cooperação na área.

7 No original: “[..] a method for reaching compromise and consensus in matters pertaining to health, usually in the face of other interests related to international politics, economics interests, and ethical values” 


\section{A doação brasileira de medicamentos antirretrovirais}

A resolução A/RES/46/182, de 1991, da Organização das Nações Unidas, estabeleceu que a assistência humanitária tem importância fundamental para vítimas de desastres naturais e outras emergências, e deve ser fornecida de acordo com os princípios de humanidade, neutralidade e imparcialidade. A soberania, integridade territorial e a unidade nacional dos Estados afetados devem ser respeitadas e, nesse contexto, a assistência humanitária deve ser fornecida com o consentimento do Estado afetado, que fará o apelo por assistência à comunidade internacional (ONU, 2016a).

Em 2004, a A/RES/58/114 reafirmou a necessidade de fortalecimento da coordenação para a assistência de emergência humanitária e os princípios de humanidade, neutralidade e imparcialidade. A resolução enfatizou ainda a importância da discussão sobre políticas no campo da assistência humanitária e a necessidade de aumentar a cooperação entre países, e também com organizações, para garantir a assistência à pessoa humana (ONU, 2016b) .

No Brasil, a criação da Coordenação-Geral de Cooperação Humanitária Internacional e combate à fome (CGFome), em 2004, e a criação do Grupo de Trabalho Interministerial sobre Assistência Humanitária (GTI-AHI), em 2006 (IPEA,/ABC, 2016), serviram como bases institucionais para a concretização e a efetivação do modelo de cooperação humanitária brasileira por meio da doação de antirretrovirais, no início dos anos 2000.

No campo da cooperação humanitária em saúde, a doação de medicamentos é uma das principais atividades desenvolvidas pelo país e, dentre essas, a doação de antirretrovirais representa o maior percentual de medicamentos doados (IPEA/ $A B C, 2016)$. No que se refere aos gastos com a doação de antirretrovirais, entre 2003 e 2015 o país gastou aproximadamente trinta e oito milhões de reais (MINISTÉRO DA SAUDE, 2016a), destacando-se o governo do presidente Luiz Inácio Lula da Silva (2003-2010), que alcançou cifras aproximadas de vinte e quatro milhões de reais. Nesse período de governo (2003 e 2010), os gastos com a doação de medicamentos foi ascendente, atingindo aproximadamente sete milhões de reais em 2009.

No período do governo da presidente Dilma Rousseff, entre os anos 2011 e 2015, o gasto do período alcançou cifras de aproximadamente catorze milhões de reais. Quando se compara o dispêndio em reais com a doação de antirretrovirais ano a ano, observa-se que em 2010 (ainda no Governo do Presidente Luiz Inácio 
Lula da Silva) o montante utilizado esteve em torno de cinco milhões, em 2011, já no Governo da Presidente Dilma Rousseff, a quantidade gasta em reais diminuiu, atingindo cifras aproximadas de três milhões. No ano seguinte, 2012, houve aumento do montante de reais empregado da doação de antirretrovirais, alcançando valores de aproximadamente nove milhões. Entre os anos de 2013 a 2015, observou-se diminuição significativa dos gastos, não alcançando estes o patamar de dois milhões (MINISTÉRIO DA SAÚDE, 2016a).

O número de antirretrovirais doado ano a ano também pode ser analisado no contexto da cooperação brasileira. No gráfico 1, observa-se o número de comprimidos antirretrovirais doados para países do continente africano, da América do Sul, Central, Ásia e para o Caricom ${ }^{8}$ entre os anos de 2003 e $2016^{9}$.

\section{Gráfico 1 - Quantidade de antirretrovirais (em número de comprimidos) doados entre os anos de 2003-2016}

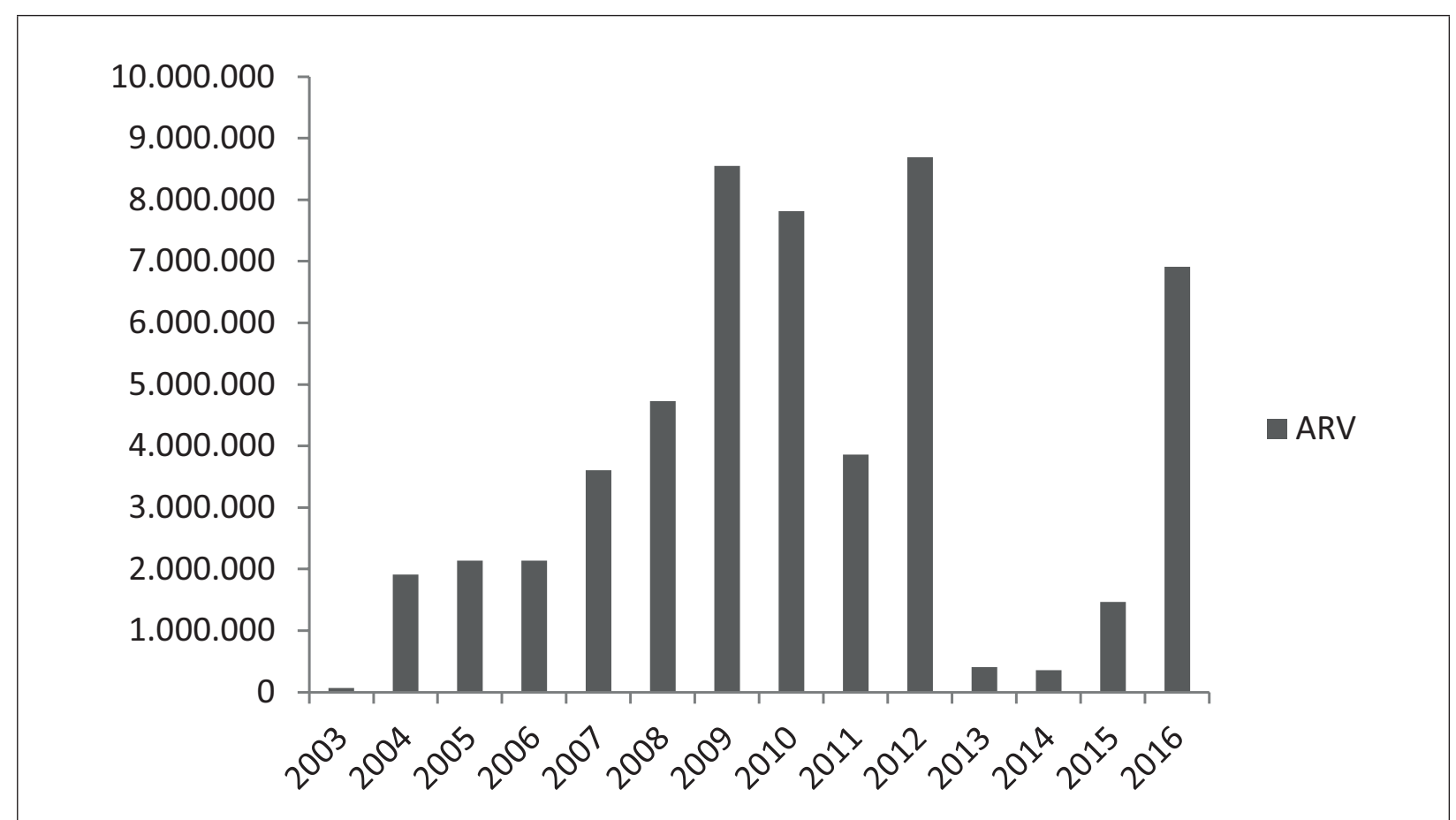

Fonte: Elaborado pela autora a partir de dados obtidos do Ministério da Saúde; Secretaria de Vigilância em Saúde; Departamento DST, AIDS e Hepatites Virais (MINISTÉRIO DA SAÚDE, 2016b).

8 O CARICOM (Comunidade do Caribe) é um organismo internacional formado por vinte países, quinze membros efetivos e cinco membros associados. O organismo foi criado em 1973, e está assentado em quatro pilares: integração econômica; coordenação de política externa; desenvolvimento social e humano; e segurança.

9 Em relação às doações de antirretrovirais, as medicações foram doadas de forma pontual, contínua ou intermitente ao longo dos anos para os países que participaram da cooperação. Todos os medicamentos doados fizeram parte dos medicamentos preconizados pela Organização Mundial da Saúde nos protocolos de tratamento da doença no mundo. 
Observa-se, a partir da análise descritiva do gráfico 1, que os anos de 2009 e 2012 obtiveram as maiores doações de medicamentos antirretrovirais, períodos em que houve também maior gasto com a doação desses medicamentos pelo governo brasileiro, como referido anteriormente. Uma das possíveis explicações para esse fato seria o aumento da demanda por cooperação na área nesses anos, que poderia ser traduzido pelo aumento do número de países que estabeleceram cooperação nesses períodos. Comparando-se os anos de 2008, 2009, 2011 e 2012, destaca-se que oito países receberam antirretrovirais em 2008, nove países em 2009, quatro países em 2011 e nove países em 2012 (MINISTÉRIO DA SAÚDE, 2016b).

Outro fator a ser considerado também na análise do gráfico 1 é que, no período estudado, houve mudança de presidentes no país, e que, embora os chefes de governo pertencessem ao mesmo partido político, a ênfase dada à referida cooperação comportou-se de forma distinta. Observa-se um padrão ascendente de doação de antirretrovirais entre 2003 e 2009, com discreta diminuição em 2010, período concernente ao governo do presidente Luís Inácio Lula da Silva, e, a partir de 2011 até o final do governo da presidente Dilma Rousseff (2016), o padrão de doação passou a ser heterogêneo, com períodos de baixíssima doação, como nos anos de 2013 e 2014. A análise do governo Dilma Rousseff ainda permite a referência a outro fator que pode ter influenciado a diminuição da cooperação na área, que é a crise político-econômica brasileira agravada durante o período do referido governo.

A doação de antirretrovirais brasileira também pode ser analisada quanto à distribuição dos países que receberam a medicação (por área geográfica) durante os governos brasileiros, entre os anos 2003 e 2016. No mandato do presidente Luiz Inácio Lula da Silva (2003-2010), Bolívia, Colômbia e Paraguai receberam na América do Sul; Nicarágua, El Salvador e República Dominicana receberam na América Central; e Cabo Verde, Burkina Faso, Guiné-Bissau, São Tomé e Príncipe e Moçambique receberam no Continente Africano. O Timor Leste foi o único país da Ásia a receber os medicamentos, e o Caricom, como organismo internacional, também recebeu doação expressiva de antirretrovirais nesse período (MINISTÉRIO DA SAÚDE, 2016b), como demonstrado no gráfico 2 a seguir. 
Gráfico 2 - Número de países, distribuídos por região geográfica, que receberam doação de ARV no governo do presidente Luiz Inácio Lula da Silva (2003-2010), incluindo o organismo internacional Caricom

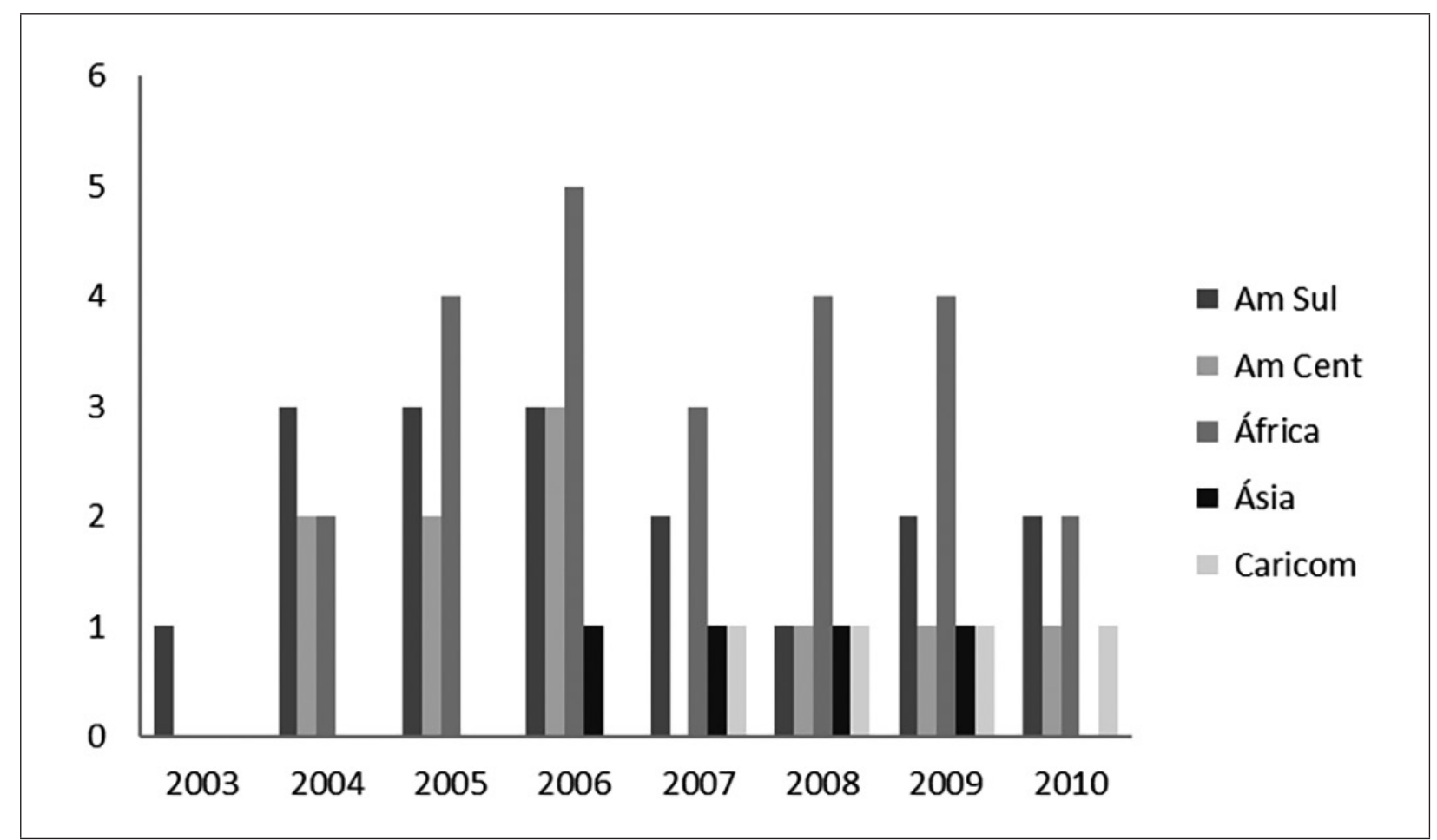

Fonte: Elaborado pela autora a partir de dados obtidos do Ministério da Saúde; Secretaria de Vigilância em Saúde; Departamento DST, AIDS e Hepatites Virais (MINISTÉRIO DA SAÚDE, 2016b).

Durante o mandato da presidente Dilma Rousseff (2011-2016) houve diminuição de gastos e de quantidade de antirretrovirais doados, como referido anteriormente. A doação desses medicamentos também pode ser analisada de acordo com a região geográfica a que os países pertencem. Nesse sentido, Bolívia, Paraguai, Equador, Peru e Chile receberam na América do Sul; República Dominicana e El Salvador receberam na América Central; e Guiné-Bissau, São Tomé e Príncipe, Burkina Faso, Cabo Verde, Líbia, Benin e Angola receberam no continente africano. O Caricom recebeu como organismo internacional, e não houve doação para países da Ásia nesse período (MINISTÉRIO DA SAÚDE, 2016b). 


\section{Gráfico 3 - Número de países, distribuídos por região geográfica, que receberam doação de ARV no governo da presidente Dilma Rousseff (2011-2016), incluindo o organismo internacional Caricom}

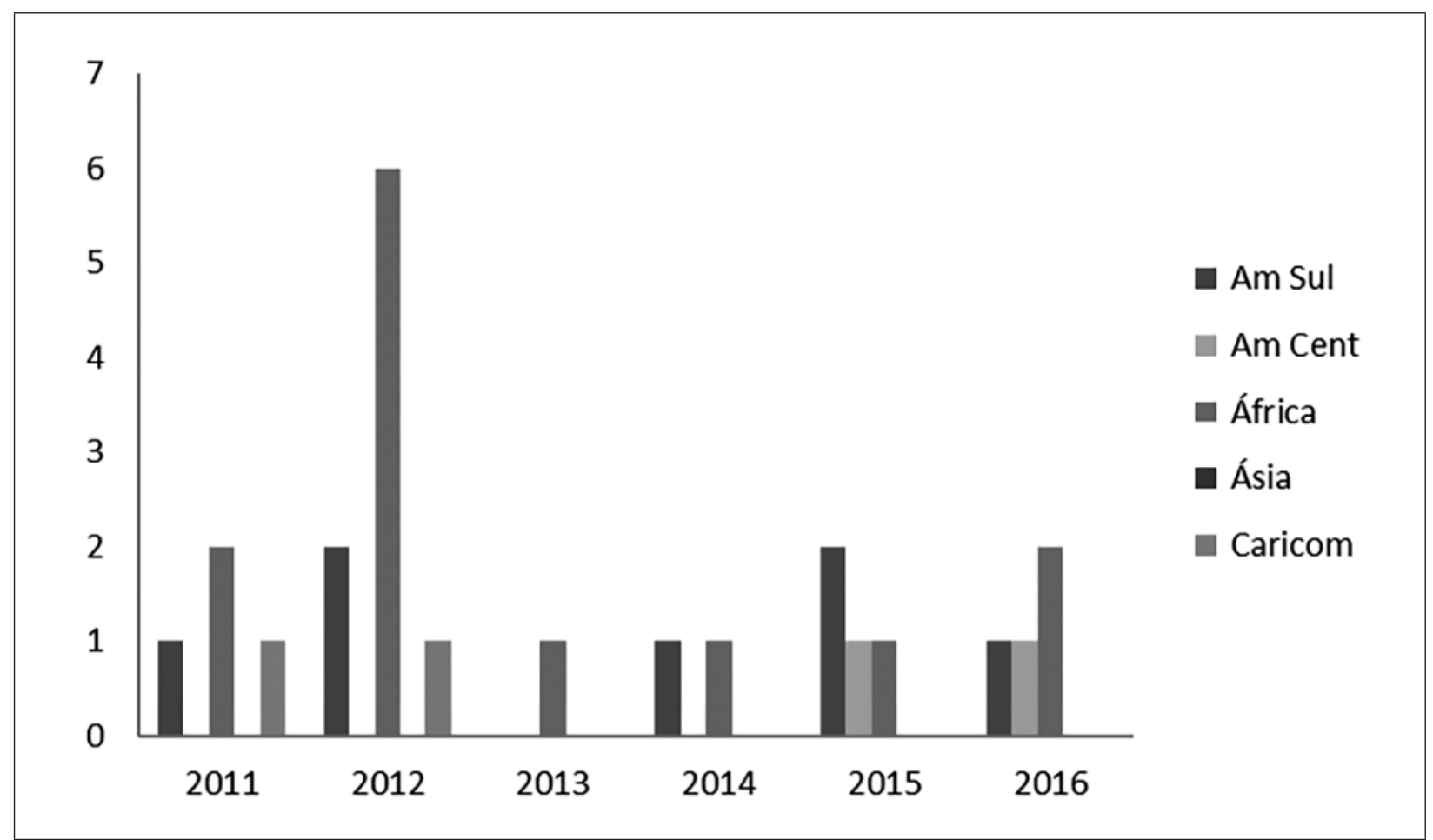

Fonte: Elaborado pela autora a partir de dados obtidos do Ministério da Saúde; Secretaria de Vigilância em Saúde; Departamento DST, AIDS e Hepatites Virais (MINISTÉRIO DA SAÚDE, 2016b).

Embora visualmente o número de países que recebeu antirretrovirais pareça menor no gráfico 3 quando comparado ao gráfico 2, países de todas as regiões, com exceção da Ásia durante o governo da presidente Dilma Rousseff, receberam medicamentos. A diferença na doação de antirretrovirais entre os dois governos se configura a partir de dois dados: a quantidade de comprimidos doados e a duração da doação. Durante o mandato do presidente Luís Inácio Lula da Silva, houve expressiva doação em quantidade de comprimidos e em tempo (medido em anos) para os países que participaram da cooperação, o que não se observou durante o governo da presidente Dilma Rousseff. Outro fator também, é o tempo de mandato da Presidente Dilma Rousseff, interrompido antes do seu término.

Outra fonte de informação importante sobre a cooperação brasileira na área de saúde e que se refere ao final dos anos 2000 está presente no relatório da AISA ${ }^{10}$

10 A Assessoria de assuntos internacionais, AISA, está vinculada ao Ministério da Saúde e responde pela elaboração das diretrizes, coordenação e implementação da política internacional do ministério, assim como pela posição brasileira sobre temas de saúde em âmbito internacional, de acordo com as diretrizes da política externa do Brasil, e em permanente articulação com as áreas técnicas das secretarias e das unidades vinculadas do Ministério da Saúde. Fonte: Ministério da Saúde, Relações Internacionais. 
publicado em 2010. O relatório descreve as atividades da cooperação brasileira na área de saúde executadas pela Divisão de Projetos da Assessoria de Assuntos Internacionais de Saúde no ano de 2009, que demonstrou que, nesse ano, havia cento e trinta e oito projetos, sendo noventa e sete na América Latina e Caribe e quarenta e um na África (MINISTÉRIO DA SAÚDE, 2010).

No que tange a países e regiões geográficas, merece destaque o projeto Laços Sul-Sul, iniciativa lançada pelo Brasil em 2004 com o objetivo de contribuir para o fortalecimento de políticas nacionais para melhorar/aumentar o acesso universal ao tratamento com antirretrovirais. O programa ofereceu tratamento com antirretrovirais de primeira linha para seis países lusófonos e dois países sulamericanos, sendo eles Bolívia e Paraguai na América Latina, e Cabo Verde, Guiné Bissau e São Tomé na África, e Timor Leste na Ásia (MINISTÉRIO DA SAÚDE, 2007 /2008). No que se refere à relação com bloco ou organismo internacional, o Paraguai é membro efetivo do Mercosul e a Bolívia membro associado, e todos os países africanos que receberam doação mais o Timor Leste pertencem à CPLP. O Chile, como membro associado do Mercosul, recebeu doação de antirretrovirais em 2016, embora não tenha participado da iniciativa Laços Sul-Sul, e Angola, membro da CPLP, embora também não tenha participado da iniciativa, também recebeu doação desses medicamentos em 2016 (MINISTÉRIO DA SAÚDE, 2016 b). O UNICEF e a UNFPA passaram a fazer parte dessa iniciativa com a função de fornecer apoio técnico e financeiro, dando enfoque maior à cooperação especialmente para gestantes, adolescentes e crianças. O objetivo principal da participação desses organismos foi o de informar esses grupos sobre seus direitos à prevenção e ao tratamento para ampliar o uso dos serviços existentes. A participação dos organismos pretendeu também intensificar a prevenção ao HIV por meio de uma melhor integração entre saúde sexual e reprodutiva, enfatizando as iniquidades de gênero, raça e etnia, disparidades geracionais e pobreza (MINISTÉRIO DA SAÚDE, 2007/2008).

Diante do exposto, as possíveis explicações para as diferenças encontradas nos gráficos 2 e 3 seriam a maior demanda dos países por essa cooperação, maior durante o governo do presidente Luís Inácio Lula da Silva, principalmente daqueles localizados na América do Sul, Caribe e continente africano. O programa Laços Sul-Sul, que beneficiou países da América do Sul e África com a doação de antirretrovirais, fortalece também o argumento de que as referidas regiões fazem parte do espectro de interesses do governo brasileiro no sistema internacional. 
A observação de que os países participantes da iniciativa são membros do Mercosul e da CPLP poderia ser considerada como fator que facilitou a doação de medicação antirretroviral ao longo do período estudado, no entanto, países não pertencentes à CPLP, como Burkina Faso, Benim e Líbia, ou ao Mercosul, como Chile, membro associado (não efetivo), também receberam doações expressivas de medicamentos no período, não se podendo, portanto, atribuir que essa condição é ou seria determinante para a doação de antirretrovirais para países que participam de blocos regionais ou organismos internacionais de que o Brasil participa.

\section{O Soft power brasileiro no contexto da cooperação Sul-Sul de combate ao HIV/AIDS}

A cooperação em saúde pode ser considerada como soft power de um país em busca da consecução de seus interesses no sistema internacional. No caso específico em questão, a cooperação Sul-Sul brasileira de combate à epidemia de HIV/AIDS, com a doação de medicamentos antirretrovirais, pode ser enquadrada nesse espectro e, nesse contexto, ser avaliada.

A cooperação no campo da saúde não utiliza a força ou coerção para se impor ou estabelecer relação entre países, como pode ocorrer no hard powe $r^{11}$. A cooperação na área atuaria, nesse sentido, por meio de atração, podendo afetar as preferências de outros Estados, estimulando, assim, o compartilhamento de ações na área.

O combate à epidemia brasileira de HIV/AIDS, desde o seu início nos anos de 1980, instituiu políticas públicas que culminaram em um controle importante da epidemia no país, o que reflete as taxas de prevalência da doença entre a população de 15-49 anos em patamares baixos (BANCO MUNDIAL, 2018). Políticas específicas para populações vulneráveis também foram instituídas, embora a taxa de prevalência do HIV/AIDS nesses grupos específicos tenha valores mais elevados que na população geral (UNAIDS, 2013).

No contexto inicial da epidemia no Brasil, o engajamento de pessoas de vários setores da sociedade civil, pessoas doentes/contaminadas pelo vírus, profissionais da saúde e ONGs começou a pressionar o governo para que fossem instituídas ações, de modo a garantir condições de atendimento e tratamento aos

11 Hard Power é quando um agente alcança o resultado esperado por meio do uso da ameaça militar e/ou de sanções econômicas ou recompensa (GRAY, 2011). 
indivíduos acometidos pela AIDS. Assentado sobre essa mobilização social foi criada a Secretaria para Acompanhamento dos Casos de AIDS, em 1984, em São Paulo, e, no ano seguinte, 1985, foi criado o Programa Nacional de Combate ao HIV/AIDS, que passou a funcionar como um centro de controle da doença no país junto com o programa de São Paulo. A partir do ano de 1986, a AIDS passou a ser de notificação obrigatória (MINISTÉRIO DA SAÚDE, 2016c).

No âmbito internacional, entre os anos de 1980 e 1990, o resultado positivo em pesquisas clínicas sobre medicamentos para o tratamento da AIDS mudou o encadeamento de ações instituídas para o combate à epidemia. O aumento da sobrevida e diminuição do número de mortes, quando se instituía o tratamento da AIDS, com a zidovudina, o AZT, permitiu que a droga fosse liberada para tratamento em indivíduos contaminados/doentes de AIDS, em 1987 (MINISTÉRIO DA SAÚDE, 2016c).

No Brasil, o governo passou a fornecer medicamentos para tratamento de infecções oportunistas ${ }^{12}$ ainda em 1988, e o AZT, para o tratamento da AIDS, passou a ser administrado a partir de 1989, por meio de compra internacional do medicamento. A produção de AZT em laboratórios nacionais ocorreu a partir de 1993, passando a ser disponibilizado na rede pública de saúde a partir de 1996. Nesse mesmo ano, foi promulgada no país a Lei 9.313, a qual garante o direito de recebimento gratuito de medicamento antirretroviral a todo indivíduo portador do vírus HIV no Sistema Único de Saúde brasileiro (MINISTÉRIO DA SAÚDE, 2016c).

O impacto da política brasileira de acesso universal aos antirretrovirais representou, entre os anos de 1996 a 2002, a diminuição de mortalidade em torno de $50 \%$, assim como a diminuição do percentual de internações hospitalares em torno de $80 \%$. Estima-se que houve uma economia do governo brasileiro, nesse período, de US $\$ 2,2$ bilhões de dólares, atribuída à menor necessidade de internação hospitalar de pessoas portadoras do vírus ou doente de AIDS, como também à diminuição do preço dos medicamentos antirretrovirais (CHEQUER, 2004). O início da produção nacional dessas medicações, bem como a capacidade de barganha nos preços de medicamentos em compras internacionais, são fatores que podem ser atribuídos à diminuição do preço dos antirretrovirais no Brasil (SOUZA, 2011).

12 Infecções oportunistas são infecções que ocorrem em decorrência da deficiência do sistema imunológico em combater o agente causador da infecção. No caso da AIDS, o vírus HIV compromete o sistema imunológico do indivíduo, destruindo as células de defesa, permitindo que vírus, bactérias e outros microrganismos - que, em condições normais, não causariam infecção - desenvolvam-se mais facilmente. 
O papel assertivo e ativista do Brasil no campo internacional também é um fator importante na questão do combate ao HIV/AIDS. Destaca-se que o país teve propostas aprovadas sobre o tema na Organização das Nações Unidas (ONU) e na Organização Mundial da Saúde (OMS) (LIMA; CAMPOS, 2010), como demonstrado no quadro 1 a seguir.

\section{Quadro 1 - Propostas brasileiras aprovadas em instituições internacionais sobre o tema do HIV/AIDS}

\begin{tabular}{|c|l|l|}
\hline ANO & \multicolumn{1}{|c|}{ ORGANIZAÇÃo } & \multicolumn{1}{c|}{ DECISÃo } \\
\hline 2001 & $\begin{array}{l}\text { ONU - Comissão de } \\
\text { Direitos Humanos }\end{array}$ & $\begin{array}{l}\text { Resolução 33/2001 - A Resolução aprovada determina que o } \\
\text { acesso a medicamentos antirretrovirais é um direito humano } \\
\text { básico. }\end{array}$ \\
\hline 2001 & OMS & $\begin{array}{l}\text { Aprovação da proposta brasileira sobre a importância da dispo- } \\
\text { nibilidade crescente de medicamentos acessíveis para as pessoas } \\
\text { afetadas pela doença. }\end{array}$ \\
\hline \multirow{2}{*}{2001} & ONU - Assembleia Geral \\
das Nações Unidas sobre & $\begin{array}{l}\text { Aprovação da Declaração de compromisso sobre HIV/AIDS, que } \\
\text { reconhece a necessidade de adoção de uma abordagem integral } \\
\text { entre prevenção, tratamento e proteção dos direitos humanos } \\
\text { como o único caminho para conter efetivamente a disseminação } \\
\text { da epidemia. }\end{array}$ \\
\hline ONU & $\begin{array}{l}\text { Participação ativa do Brasil no Fundo Global para o Combate } \\
\text { à AIDS, Tuberculose e Malária, lutando por uma participação } \\
\text { igualitária entre países ricos e em desenvolvimento em seu } \\
\text { principal órgão decisório, o Corpo Diretivo. }\end{array}$ \\
\hline
\end{tabular}

Fonte: elaborado pela autora a partir dos autores Lima e Campos (2010, p. 124)

Ressalta-se também que o país continuou participando ativamente em fóruns internacionais onde a temática foi tratada de forma direta ou indireta, tais como na aprovação do Acordo TRIPS e Saúde Pública na Organização do Comércio, em 2001, que permite que os países adotem medidas para proteger a saúde pública. O Brasil participou também ativamente na Cúpula do Milênio, em 2001, que teve como um de seus objetivos combater a AIDS, a Malária e outras doenças.

Na Organização Mundial da Saúde, o Brasil defendeu a ideia de que a organização deveria dispor de um mandato que lhe permitisse avaliar as implicações para a saúde pública e da proteção aos direitos de propriedade intelectual durante a $56^{\mathrm{a}}$ Assembleia, em 2003. No ano seguinte, o país participou da aprovação da Resolução n.57.14 da OMS, a qual reafirma os direitos dos países membros da organização em utilizar as flexibilidades do TRIPS e de acordos de comércio regionais e bilaterais. No ano de 2007, o país participou da aprovação 
da Resolução 60.30 sobre "Saúde Pública, Inovação e Propriedade Intelectual", onde a organização assume o compromisso de apoiar tecnicamente os países que desejassem utilizar as flexibilidades do Acordo TRIPS (BARBOZA; PINHEIRO; PIRES-ALVES, 2017).

A participação do país em grupos de pesquisa internacionais para o desenvolvimento de uma vacina eficaz contra o vírus HIV também demonstra o papel ativo, assertivo e ativista no campo de ações para o combate à epidemia mundial. A pesquisa para a cura da AIDS teve início a partir da descoberta do agente causador, o vírus HIV, e atualmente vários países têm pesquisas na área, sendo o maior número delas atribuído aos Estados Unidos. Estima-se que, desde 1987, já tenham sido testadas mais de trinta vacinas contra o HIV. Na atualidade, vários países colaboram/cooperam para a descoberta de uma ou várias vacinas contra a AIDS, como Brasil, China, Cuba, Haiti, Quênia, Peru, Tailândia, Trinidad e Uganda (OMS, 2014). Nesse mesmo campo de pesquisa, destaca-se também outra iniciativa brasileira, que foi a criação da Rede Tecnológica Internacional para Vacina da AIDS, em 2004, e da qual participam Brasil, China, Cuba, Nigéria, Rússia, Tailândia e Ucrânia (FIOCRUZ, 2018).

Quando se considera a cooperação estabelecida pelo Brasil como instrumento de soft power do país no sistema internacional, onde estariam as bases concretas para tal afirmação? A análise das fontes de soft power, tais como a cultura, os valores políticos, as instituições, a personalidade de um líder e a política externa do país (NYE, 2004), orientam a resposta para essa pergunta.

A cultura de um país é considerada uma fonte de poder brando, significando, nesse contexto, o conjunto de valores e práticas que dão sentido à sociedade que se está analisando. Para o contexto do tema abordado, considerar-se-á o termo cultura política, cujo significado, segundo Almond e Verba (1963, p. 12) referese a "orientações e atitudes políticas em relação ao sistema político e suas várias partes, e atitudes em relação ao papel do indivíduo nesse sistema"13.

O início da epidemia de HIV/AIDS no Brasil e no mundo ficou marcada pelo grande número de mortes entre pessoas jovens naquele período, pelo não conhecimento do agente causador e pela impossibilidade de tratamento adequado das pessoas afetadas. O fornecimento da primeira medicação para o tratamento da AIDS, o AZT, no Brasil, a partir de 1989, por meio de compra internacional da

13 No original: “[...] political orientations-attitudes toward the political system and its various parts and attitudes toward the role of the self in the system" 
medicação, foi uma das respostas à mobilização de vários setores da sociedade (MINISTÉRIO DA SAÚDE, 2016c).

A constituição brasileira, em seu artigo 196, determina que a saúde é um direito de todos e dever do Estado e, nesse sentido, funciona como base normativa que permite o acesso universal ao tratamento para a AIDS a todos os brasileiros que dele necessitarem. A instituição dessa política social, desde o período inicial da epidemia de HIV/AIDS no país, contribuiu sobremaneira para o maior controle da doença, tendo como consequência positiva a diminuição do número de mortes e pessoas doentes, além de contribuir a longo e médio prazo para a manutenção da baixa taxa de prevalência da doença na população entre 15-49 anos (BANCO MUNDIAL, 2018).

No Brasil, a Fiocruz (Fundação Oswaldo Cruz) e outros seis laboratórios públicos produzem parte dos medicamentos antirretrovirais que abastecem a demanda doméstica para o tratamento de pessoas doentes/contaminadas pelo vírus HIV no Sistema Único de Saúde, sendo a outra parte fornecida pelo governo federal por meio de compra internacional de medicamentos (FIOCRUZ, 2018a). Além do fornecimento gratuito de antirretrovirais produzidos no Brasil e daqueles importados para o tratamento do HIV/AIDS na rede pública de saúde, políticas domésticas incluem também a inauguração da primeira fábrica estatal de preservativos no Acre, em 2008, aproveitando o látex produzido a partir dos seringais nativos da região; a mudança do protocolo de antirretrovirais em 2013, sendo iniciada a medicação em qualquer paciente portador do vírus independente do nível de CD4 14; a implantação do projeto piloto profilaxia pré-exposição, em 2013, para pacientes considerados de grupos de risco, e com sorologia negativa para o HIV (entre eles estão homossexuais masculinos, profissionais do sexo, travestis, transexuais e usuários de drogas), e que farão uso diário de antirretrovirais a fim de diminuir as chances da infecção pelo vírus; a sanção da Lei 12.984, em 2014, que pune com reclusão de um a quatro anos, além de multa, o indivíduo que praticar condutas discriminatórias contra o portador de HIV (CEZAR; DRAGANOV, 2018).

No campo internacional, pode-se destacar a participação do Brasil em instâncias internacionais, como as organizações citadas anteriormente (LIMA; CAMPOS, 2010), nas quais se consolidaram o papel assertivo desempenhado pelo país no cenário internacional em questões relativas ao tema, como a defesa de

14 CD4 são células do sistema imunológico (linfócitos) e o principal alvo do vírus HIV. O número de CD4 diminui com a evolução da patologia. Quanto menos linfócitos CD4, maior a vulnerabilidade do sistema imunológico e maior o risco de complicações e infecções. Fonte: Portal Hospitais Brasil. 
que o acesso aos medicamentos contra a AIDS é um direito humano e de que o tratamento deve estar acessível a todo cidadão. Nesse contexto, destaca-se também a participação brasileira nas conferências internacionais de AIDS, em que, no ano de 2018, o país participou mais uma vez como debatedor e apresentador de trabalhos, tendo sido convidado pela Organização Mundial da Saúde para discutir temas relacionados ao tratamento e inovação do tratamento da doença no Brasil (MINISTÉRIO DA SAÚDE, 2018).

Outra participação brasileira no contexto internacional foi a criação da UNITAID, em 2006, junto com França, Noruega, Reino Unido e Chile, com o objetivo de fornecer fontes alternativas de financiamento para ações contra a epidemia de HIV/AIDS no mundo. Ao longo dos anos, outros países entraram para a organização, que atualmente (2018) é composta por Brasil, Camarões, Chile, Congo, Chipre, França, Guiné, Luxemburgo, Madagascar, Mali, Maurícius, Níger, Noruega, República da Coréia, Espanha e Reino Unido. Participa ainda como doador a Fundação Bill e Melinda Gates (OMS, 2018).

As ações citadas anteriormente fortalecem a ideia do combate à AIDS no país e fora dele, e estiveram e estão embasadas em valores sociais presentes desde o início da epidemia no país, tais como: o direito à saúde e, por consequência, o direito ao acesso a todo tipo de tratamento; o direito à saúde como direito humano; e a ideia de não descriminação à pessoa portadora/doente com o vírus da AIDS. O jornal inglês “The Lancet”, uma das mais importantes publicações científicas da área médica, divulgou um estudo, em 2014, mostrando que o tratamento para AIDS no Brasil é mais eficiente que a média global. Segundo o estudo, as mortes em decorrência do vírus HIV no país caíram a uma taxa anual de 2,3\% entre 2000 e 2013, enquanto a média global apresenta uma queda de 1,5\% ao ano (FIOCRUZ, 2018b).

A personalidade de um líder também é considerada como fonte de poder brando. Durante o governo do presidente Luiz Inácio Lula da Silva (2003-2010), a temática do combate ao HIV/AIDS recebeu importância, fato comprovado pela quantidade de ações na área (doação de antirretrovirais, os projetos técnicos, ações na área de educação; projetos científico-tecnológicos na área e doação para organismos internacionais). Destaca-se, aqui, a doação de medicamentos antirretrovirais para vários países da América do Sul, Central, Ásia e África, e para organismos internacionais, bem como a importância do tema, presente em discursos do presidente em fóruns internacionais, como os proferidos na LIX Assembleia Geral das Nações Unidas em 2004; na 5a . Conferência de Chefes de 
Estado e de Governo da CPLP, em julho de 2004; e na Cúpula África-América do Sul que ocorreu na Nigéria em 2006 (PUENTE, 2010).

Comparando-se o número de atos internacionais na área de combate ao HIV/AIDS, entre os anos de 1995 e 2016, observa-se também um aumento considerável de atos durante o mandato do presidente Luiz Inácio Lula da Silva, quando comparado aos governos do presidente Fernando Henrique Cardoso e da presidente Dilma Rousseff. O número de acordos e ajustes a acordos de cooperação relacionados ao combate do HIV/AIDS foram cinco no governo do presidente Fernando Henrique, vinte e dois durante o governo do presidente Luiz Inácio Lula da Silva, não havendo registro de atos internacionais na área durante o governo da presidente Dilma Rousseff (MINISTÉRIO DAS RELAÇÕES EXTERIORES, 2016).

O último ponto a ser discutido sobre as fontes de soft power inclui a política externa brasileira na área como ação que legitima e que tem autoridade moral ao ser empreendida no campo internacional. As medidas implementadas para o combate à epidemia de AIDS no país, desde o início dos casos, contruíram as bases que permitiram instituir ações de cooperação internacional no início dos anos 2000. Nesse contexto, a cooperação Sul-Sul brasileria de combate ao HIV/AIDS contitui-se como um campo específico de atuação da política externa brasileira no sistema internacional.

A doação de medicamentos antirretrovirais foi e continua sendo uma das ações implementadas pelo Brasil no combate à epidemia mundial de HIV/AIDS. A política de acesso universal aos medicamentos contra AIDS do governo brasileiro, responsável, em parte, pela baixa prevalência da doença no país, permite que outros países em desenvolvimento demandem pela cooperação brasileira na área, como tentativa de diminuir a prevalência da doença em seus países, bem como aumentar o acesso ao tratamento do HIV/AIDS para os seus nacionais.

No contexto da doação de antirretrovirais, observa-se que, no governo do presidente Luiz Inácio Lula da Silva, as ações foram instituídas de forma mais assertiva em comparação ao governo da presidente Dilma Rousseff. A quantidade de medicamentos doados, a quantidade de países que receberam medicamentos, a importância dada à temática em discursos oficiais em encontros internacionais, bem como o tempo de doação das medicações para os países ao longo de seus governos, balizam essa observação. Destaca-se também as propostas brasileiras apresentadas e aprovadas na área de combate à epidemia mundial de AIDS, apresentadas em instituições internacionais, já citadas anteriormente. 
No âmbito das instituições internacionais, ressalta-se também o combate à epidemia mundial de AIDS no contexto dos BRICS (agrupamento formado por Brasil, Rússia, Índia, China e África do Sul). Na cooperação internacional para o combate à epidemia, os Estados Unidos configuram-se como o maior doador internacional, responsável por quase cinquenta por cento da assistência internacional para o combate à doença no mundo, sendo seguido por países europeus pertencentes à Organização Econômica para Cooperação e Desenvolvimento (OCDE), países europeus não pertencentes à OCDE, o Fundo Global de Combate à Aids e Malária e os BRICS (UNAIDS, 2013).

A assistência financeira dos BRICS, entre os anos de 2007-2008, contribuiu com aproximadamente US\$200 milhões de dólares para iniciativas no campo da saúde global e, dentro delas, a doação para o Fundo Global de Combate à AIDS, Malária e Tuberculose (CHATUVERDI; THORSTEINSDÓTTIR, 2012). Embora a doação para ações de combate ao HIV/AIDS no mundo pelos BRICS, em torno de 0,1\% (UNAIDS, 2013), seja infinitamente menor do que a maior parte dos países citados anteriormente, a importância da doação deve ser analisada sob o ponto da política internacional. A saúde é uma das temáticas de interesse dos países que formam os BRICS, sendo a mesma discutida nas reuniões dos ministros da saúde tanto no contexto das cúpulas, quanto nas reuniões dos ministros da Saúde dos BRICS às margens da Assembleia da Organização Mundial da Saúde, que ocorreram nos anos de 2011 e 2012, respectivamente $64^{\mathrm{a}}$ e $65^{\mathrm{a}}$ Assembleias Gerais da OMS (HERZ; FLORENTINO; MIRANDA, 2012).

A importância política da doação de antirretrovirais pelos países BRICS referese à participação dos mesmos como países em desenvolvimento se portando como doadores internacionais, além do posicionamento dos mesmos em fóruns internacionais de discussão da temática, tais como a OMS e a ONU, demonstranto o alinhamento de ideias e ações que tentam equilibrar a tomada de decisões na área e, por conseguinte, melhor distribuição de benefícios entre países desenvolvidos e em desenvolvimento.

Retomando a discussão da relação entre saúde e política externa, citada anteriormente, pode-se inferir que a coopração Sul-Sul brasileira para o combate ao HIV/AIDS é um instrumento da política externa do país quando se considera que questões relacionadas à AIDS foram e continuam sendo discutidas em fóruns internacionais como a ONU e a OMS, nas cúpulas dos BRICS, no Grupo de Trabalho Saúde do IBAS, no Mercosul, na CPLP e em conferências internacionais, como a Conferência Internacional de AIDS, tendo repercussão tanto nacionalmente como 
internacionalmente. A cooperação na área, nesse sentido, serve aos interesses nacionais, uma vez que aumenta a relação entre os países, podendo servir como “via” facilitadora para novas interações entre os Estados.

Considera-se, portanto, que as fontes de soft power estão presentes na cooperação Sul-Sul brasileira para o combate ao HIV/AIDS e, desse maneira, o país, durante o período estudado, atuou internacionalmente por meio do mesmo, na área em destaque.

\section{Considerações finais}

A cooperação Sul-Sul brasileira na área de combate ao HIV/AIDS constituiu-se como um instrumento de soft power brasileiro no contexto internacional. A cultura política brasileira, no que se refere às políticas sociais que deram suporte ao combate à epidemia no país, contribuiu e contribui, sobremaneira, para os baixos níveis de prevalência da doença na polupação entre 15 e 49 anos até os dias atuais, tendo, como um dos principais pilares, a politica de acesso universal ao tratamento, um dos fatores para a baixa prevalência da doença no país, dado já referido anteriormente.

As participações brasileiras em fóruns como a ONU, OMC e OMS, em 2001, destacadas anteriormente, defendendo o acesso universal aos medicamentos antirretrovirais, bem como o acesso aos medicamentos como um direito humano, permitiram a visão do Brasil por outros países, como um defensor de questões relacionadas ao tema.

O combate à epidemia de HIV/AIDS, uma das temáticas prioritárias do governo do presidente Luiz Inácio Lula da Silva, expresso em encontros internacionais, como os citados anteriormente, e concretizado por meio da cooperação internacional na área, ampliaram a participação brasileira no sistema internacional, chamando atenção, por conseguinte, de outros países para a cooperação com países em desenvolvimento.

Por fim, a cooperação brasileira Sul-Sul de combate ao HIV/AIDS compreendida como instrumento da política externa brasileira, serve aos interesses nacionais quando aumenta a relação entre os países, ao mesmo tampo em que projeta uma imagem positiva e de um país que quer participar e participa de questões relativas ao combate da epidemia em seu próprio território e no sistema internacional.

Considera-se, portanto, que as políticas doméstivas adotadas pelo Brasil ao longo dos anos no contexto da epidemia de HIV/AIDS, culminando no início dos 
anos 2000 com as primeiras ações de cooperação internacional na área, funcionaram como instrumento de soft power do país e fonte de atração de outros países para estabelecer ações na área.

\section{Referências}

AGÊNCIA BRASILEIRA DE COOPERAÇÃO (ABC). Cooperação Sul-Sul. Disponível em: < http://www.abc.gov.br/Projetos/CooperacaoSulSul. Acesso em: 10 jan 2018.

ASSESSORIA DE ASSUNTOS INTERNACIONAIS (AISA). O que fazemos.Disponível em: http://portalms.saude.gov.br/assessoria-internacional > . Acesso em: 24 jan 2015.

ALMOND, Gabriel A.; VERBA, Sidney. The Civic Culture or The Civic Culture: Political Attitudes and Democracy in Five Nations. California. Sage Publications. 1963.

BALDWIN, David A. Neorealism and Neoliberalism. The Contemporary Debat. New York, Columbia University Press. 1993.

BANCO MUNDIAL. Prevalence of HIV, total (\%population ages 15-49). Disponível em: < https://data.worldbank.org/indicator/SH.DYN.AIDS.ZS > . Acesso em: 20 mar 2018.

BARBOZA, Tayná Marques T.; PINHEIRO, Leticia.; PIRES-ALVES, Fernando. O diálogo entre saúde e política externa brasileira nos governos de Fernando Henrique Cardoso (1995-2002) e Luís Inácio Lula da Silva (2003-2010). Rev. Carta Inter, Belo Horizonte, v. 12, n. 3, 2017, p. 175-198. Acesso em: 12 fev 2018.

BATISTELLA, Carlos. Abordagens contemporâneas do conceito de Saúde in O território e o processo saúde-doença. Organizado por Angélica Ferreira Fonseca e Ana Maria D’Andrea Corbo. - Rio de Janeiro: EPSJV/Fiocruz. 2007. Disponível em: < https://edisciplinas.usp.br/ pluginfile.php/3120150/mod_resource/content/2/O\%20territ \% C3 \% B3rio \% 20e \% 20 o \% 20processo \%20sa \% C3 \% BAde-doen \% C3 \% A7a.pdf > . Acesso em: 10 mar 2018. BOBBIO, Norberto. Estado, Governo e Sociedade. Fragmentos De Um Dicionário político. $20^{\mathrm{a}}$ ed. Rio de Janeiro/São Paulo. Paz e Terra. 2017.

CARICOM. Who we are. Disponível em: < http://www.caricom.org/ > . Acesso em: 15 dez 2017. CEZAR, Vagner Mendes; DRAGANOV, Patricia Bover. A História e as Políticas Públicas do HIV no Brasil sob uma Visão Bioética. Ensaios Cienc., Cienc. Biol. Agrar. Saúde, v. 18, n. 3, p. 151-156, 2014. Disponível em: < http://www.redalyc.org/html/260/26042165006/ > . Acesso em: 15 set 2018 .

CHATUVERDI, Sachin; THORSTEINSDÓTTIR, Halla. BRICS and South-South Cooperation in Medicine: Emerging Trends in Research and Entrepreneurial Collaborations. Discussion paper \#177. Research and Information System for Developing Countries. 2012. Disponível em: < http://www.ris.org.in/brics-and-south-south-cooperationmedicine-emerging-trends-research-and-entrepreneurial > . Acesso em: 12 mar 2018. 
CHEQUER, Pedro. A Resposta Nacional ao HIV/AIDS. 2004. Disponível em: < http://www.who. int/intellectualproperty/events/HIVAIDSPedroChequer.pdf > . Acesso em: 15 dez 2017. CORRÊA, Marcio Lopes. Prática Comentada de Cooperação Internacional. Entre a Hegemonia e a busca de autonomia. Edição do autor, Brasília, 2010.

DUTTA, Abhinav. The Concept of Soft Power: A Critical Analysis in International Affairs Forum. Disponível em: < http://www.ia-forum.org/Content/ViewInternalDocument. cfm? ContentID $=8393>$. Acesso em: 15 set 2018 .

FERGUSON, Niall. Think Again: power in Foreign Policy. 2009. Disponível em: < https:// foreignpolicy.com/2009/11/03/think-again-power/ > . Acesso em: 16 set 2018.

FIOCRUZ. Rede de cooperação em HIV/AIDS. Disponível em: < http://www6.ensp. fiocruz.br/radis/revista-radis/31/reportagens/rede-de-cooperacao-em-hivaids > . Acesso em: 10 feb 2018.

. Fiocruz produz mais de 150 milhões de antirretrovirais e desenvolve novas formulações para atender público infantil. 2018a. Disponível em: < https://agencia. fiocruz.br/fiocruz-produz-mais-de-150-milhoes-de-antirretrovirais-e-desenvolvenovas-formulacoes-para-atender > . Acesso em: 20 set 2018.

. Medicamento 3 em 1 para a AIDS começa a ser distribuído em todo o país. 2018b. Dsiponível em: < https://www.bio.fiocruz.br/index.php/noticias/903-medicamento3-em-1-para-tratamento-da-aids-comeca-a-ser-distribuido-em-todo-o-pais > . Acesso em: 20 set 2018 .

GRAY, Colin S. Hard power and Soft Power: The utility of Military Force as an instrument of police in the $21^{\text {st }}$ Century. Strategic Studies Institute Publications. 2011. Disponível em: < http://ssi.armywarcollege.edu/pdffiles/pub1059.pdf > . Acesso em: 15 set 2018. HERZ, Monica; FLORENTINO, Lucas Perez; MIRANDA, Victor Costa Velho. A coordenação dos BRICS nos fóruns multilaterais. BRICS Policy Center - Policy Brief. 2012. Disponível em: < http://bricspolicycenter.org/homolog/uploads/trabalhos/5782/ doc/1368571065.pdf > . Acesso em: 10 jun 2016.

HOSPITAIS BRASIL. Aids: o que é CD4 e seu papel nos 30 anos de combate à doença no Brasil. 2018. Disponível em: < http://portalhospitaisbrasil.com.br/aids-o-que-e-cd4e-seu-papel-nos-30-anos-de-combate-a-doenca-no-brasil > . Acesso em: 20 set 2018. IDEC. Acordo Comercial entre Índia e UE pode Prejudicar acesso a medicamentos. 2018. Disponível em: < https://idec.org.br/em-acao/em-foco/acordo-comercial-entre-indiae-ue-pode-prejudicar-acesso-a-medicamentos > . Acesso em: 30 mar 2018.

INSTITUTO DE PESQUISA ECONÔMICA APLICADA; AGÊNCIA BRASILEIRA DE COOPERAÇÃO (IPEA/ABC); MINISTÉRIO DAS RELAÇÕES EXTERIORES (MRE) Cooperação Brasileira para o Desenvolvimento Internacional. 2011-2013. LIMA, B. J. B (Editor). Brasília: Ipea: ABC, 2016. Disponível em: <www.ipea.gov.br > . Acesso em: 10 out 2016. 
KICKBUSCH, Ilona. 21st Century Health Diplomacy: A new Relationship Between Foreign Policy and Health in $21^{\text {st }}$ Century Global Health Diplomacy edited by Thomas E. Novotony, Ilona Kickbusch and Michaela Todd. Singapore. Published by World Scientific Publishing Co. Pte. Ltd. 2013.

LEITE, Iara Costa, SUYAMA, Bianca.; WAISBICH, Laura Trajber. Para além do tecnicismo. A cooperação brasileira internacional para o desenvolvimento e os caminhos para a sua efetivação e democratização. Articulação Sul. 2013. disponível em: < http:// articulacaosul.org/wp-content/uploads/2014/07/Policy_Briefing_Para_alem_do_ tecnicismo.pdf > . Acesso em: 10 jun 2016.

LIMA, Thaísa Gois Farias de Moura Santos; CAMPOS, Rodrigo Pires. O perfil dos projetos de cooperação técnica brasileira em AIDS no mundo: explorando potenciais hipóteses de estudo. RECIIS - R. Eletr. de Com. Inf. Inov. Saúde. Rio de Janeiro. 4(1):119-133, mar, 2010.

MATSUDA, Takeshi. Soft Power and its perils: US Cultural Policy in Early Postwar Japan and Permanent Dependency.US, Stanford University Press, pp. 4-6. 2007

MCCLORY, Jonathan. The Soft Power 30. A Global Ranking of Soft Power. 2018. USC Center on Public Diplomacy. Disponível em: < https://softpower30.com/ > Acesso em: 10 sep 2018.

MINISTÉRIO DA SAÚDE. BANCO DO BRASIL. Gasto do governo brasileiro em Reais entre 2002-2012, e de 2011 a 2015, com a cooperação brasileira de combate ao HIV/AIDS. Informação fornecida pelo Ministério da Saúde por meio do eSic. (2016a)

MINISTÉRIO DA SAÚDE. DEPARTAMENTO DE DST, AIDS E HEPATITES VIRAIS. SECRETARIA DE VIGILÂNCIA EM SAÚDE. Doações de antirretrovirais brasileiras entre 2013-2016. (2016b).

MINISTÉRIO DA SAÚDE. DEPARTAMENTO DE DST, AIDS E HEPATITES VIRAIS. História da AIDS. (2016c). Disponível em: < http://www.aids.gov.br/pagina/historia-da-aids > . Acesso em: 01 dez 2014.

MINISTÉRIO DA SAÚDE. Brasil participa da $22^{\text {a }}$ Conferência Internacional de AIDS. (2018). Disponível em: < http://portalms.saude.gov.br/noticias/agencia-saude/43874brasil-participa-da-22-conferencia-internacional-de-aids > . Acesso em: 25 set 2018 . . Relatório de gestão 2009 da Assessoria de Assuntos Internacionais de Saúde (AISA)/ Ministério da Saúde, Gabinete do Ministro, Assessoria de Assuntos Internacionais de Saúde. Brasília: Editora do Ministério da Saúde, 2010.

. UNAIDS;UNICEF;UNFPA.LAÇOS SUL SUL (2007/2008) Disponível em: < http:// www.unicef.org/brazil/pt/07_08_LSSBooklet.pdf > . Acesso em: 15 dez 2014.

MINISTÉRIO DAS RELAÇÕES EXTERIORES (MRE). Sistema de Atos Internacionais. (2016). Disponível em: < http://dai-mre.serpro.gov.br/ > . Acesso em: 10 out 2016. 
NYE JR, Joseph. S. Soft power. The means to success in world politics. New York, Public Affairs. 2004. pp. 191.

OMS. HIV Vaccines. (2014). Disponivel em: < http://www.who.int/hiv/topics/vaccines/ Vaccines/en/ > . Acesso em: 09 jan 2015. . UNITAID. Innovation for global health. (2018). Disponível em: < http://www.who. int/global-coordination-mechanism/working-groups/unitaid.pdf > . Acesso em: 20 set 2018 .

ONU. A/RES/46/182 (2016a). Disponível em: < http://www.un.org/documents/ga/res/ 46/a46r182.htm > . Acesso em: 17 out 2016.

. A/RES/58/114. (2016b)Disponível em: < http://www.preventionweb.net/files/ resolutions/N0350142.pdf $>$. Acesso em: 17 out 2016.

PUENTE, Carlos Alfonso Iglesias. A cooperação técnica horizontal brasileira como instrumento da política externa: evolução da cooperação técnica com países em desenvolvimento - CTPD - período 1995-2005. Brasília. FUNAG, 2010.

SOUZA, Andre de Mello e Acordo sobre os Aspectos dos Direitos De Propriedade Intelectual relacionados ao Comércio (Trips): Implicações e Possibilidades para a Saúde Pública no Brasil. IPEA. Texto para discussão 1615. 2011, p. 1-37. Disponível em: < http://www.ipea.gov.br/sites/000/2/publicacoes/tds/TD_1615_WEB.pdf > . Acesso em: 15 set 2012

UNAIDS. Global Report. UNAIDS report in the global AIDS epidemic (2013). Disponível em: < http://www.unaids.org/sites/default/files/en/media/unaids/contentassets/ documents/epidemiology/2013/gr2013/UNAIDS_Global_Report_2013_en.pdf > . Acesso em: 07 out 2014.

UNAIDS DATA. Disponível em: < http://www.unaids.org/sites/default/files/media_ asset/20170720_Data_book_2017_en.pdf > . Acesso em: 01 mar 2018

UNITAID. About us. 2018. Disponível em: < https://unitaid.eu/about-us/\#en > Acesso em: 15 mar 2018.

WALTZ, Kenneth N. Theory of International Politics. Reading, Mass:Addison-Wesley. 1979. 